\title{
ACCIDENT INJURY OF HYENA: A CASE STUDY
}

\author{
SUDEEP SOLANKI ${ }^{1}$, SANDHYA MORWAL ${ }^{2}$ \& AJAY CHOUHAN ${ }^{3}$ \\ ${ }^{1}$ Assistant Professor, Department of Veterinary Microbiology, VUTRC, Sirohi, \\ Rajasthan University of Veterinary \& Animal Sciences, Bikaner, Rajasthan, India
}

${ }^{2}$ Assistant Professor, Veterinary Medicine, TVCC, College of Veterinary \& Animal Science, Vallabhnagar,

Udaipur, Rajasthan University of Veterinary \& Animal Sciences, Bikaner, Rajasthan, India

${ }^{3}$ Veterinary Officer, Poly clinic, Department of Animal Husbandry, Sirohi, Rajasthan, India

\begin{abstract}
A wildife case reported in the winter month last year at Veterinary Polyclinic, Sirohi(Rajasthan). A three year old male Hyena (Hyaena hyaena) seriously injured was brought by Forest department. According to forest department, the hyena was lying in deep inside bushes and was unable to move, near Mandar village of Sirohi district until it was rescued last night. Hyena had an injury of the sacral region with paralysis of hindquarter, injury at the pelvic region with maggot would more than 5 days old, bruises above the right eye and neck region. The wild animal was examined for fracture and other internal injuries. Physical examination of hyena showed, difficulty in breathing, nasal discharge, paralysis of hindquarter without visible sign of fractures. The observed clinical signs were hyper-salivation; cardiac irregularities (arrhythmia) with off feeding and rapid gasping breathing. Hyena was treated with antiseptic dressing of wounds and maggot wound with potassium paramagnet and turpentine oil, IV fluid therapy (normal saline, 500ml), IV Amikacin $500 \mathrm{mg} / \mathrm{ml}$, IM Meloxicam $10 \mathrm{ml}$, Inj. Antihistamine $5 \mathrm{ml}$, Inj. Dexamethasone $10 \mathrm{ml}$. It was taken to PFA rescue center but no quick improvement was seen till evening. Despite all care and treatment, the Hyena died the next morning.

KEYWORDS: Hyaena Hyaena, Accident, Striped \& Sirohi
\end{abstract}

Received: Sep 28, 2018; Accepted: Oct 18, 2018; Published: Nov 03, 2018; Paper Id.: IJASRDEC20188

\section{INTRODUCTION}

Striped hyena (Hyaena hyaena) is a near-threatened large carnivore known to occur in arid and semi-arid landscapes in many parts of the world.

Hyenas, which are carnivorous animals, belonging to the Hyaenidae family are largely found in Africa, theMiddle East and Indian sub-continents (Ahmed et al., 2012). They generally live in solitary but have some social organizations (Alam, 2011). In India, only striped hyenas (Hyaena hyaena) are found (Prater, 1980).

The striped hyena is a monogamous animal, with both males and females assisting one another in raising their cubs. A nocturnal animal, the striped hyena typically only emerges in complete darkness and is quick to return to its lair before sunrise.

The presence of domestic mammals in the scat remains implied that the striped hyena might frequently visit human habitation in search for food and hence, a potential conflict between human and wildlife might arise.

Gajera et al. (2009) reported them as the most widespread species in India. They are primarily nocturnal animals that only emerge from their dens after complete darkness and return quickly before sunrise (Kruk, 1976; 
Alam, 2011).

The present study was performed during the seasons of winter and summer in the semi-arid Gir forest.

\section{CASE HISTORY AND OBSERVATIONS}

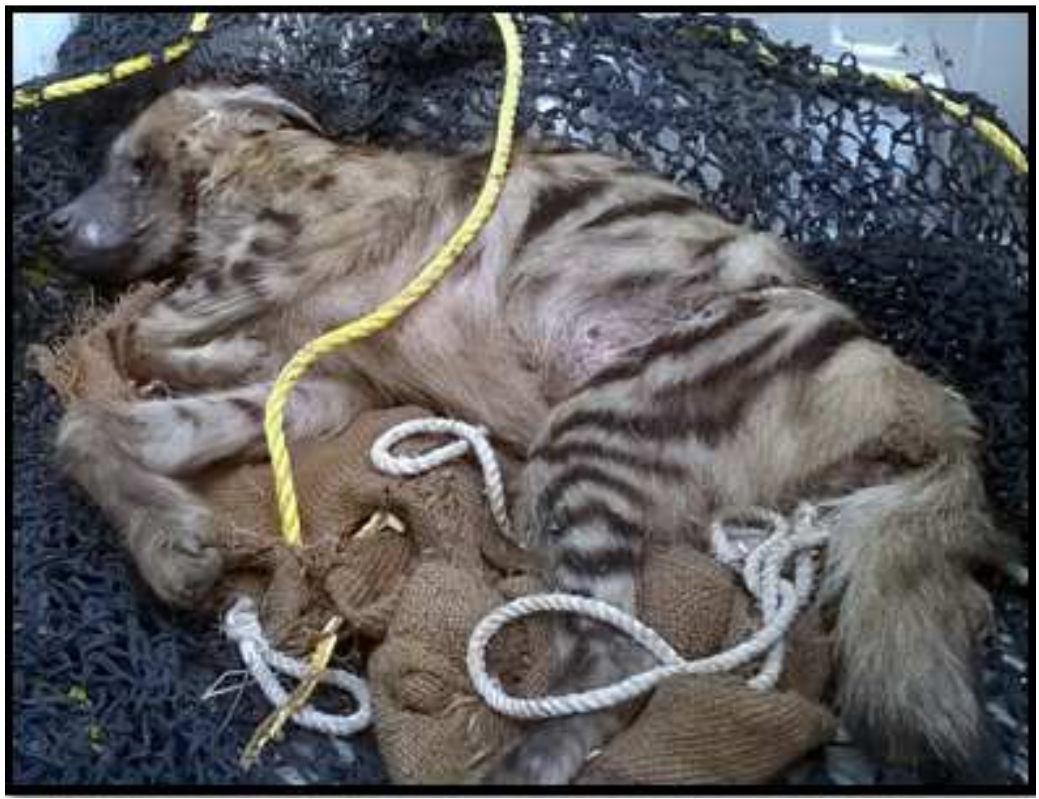

Figure 1

A five days old case of striped male hyena (3yearold) fairly massive, injured in a road accident was brought by forest ranger to Polyclinic Sirohi for treatment. Hyena presented to the clinics was observed thoroughly. Physical examination of hyena showed, difficulty in breathing, nasal discharge, paralysis of hindquarter without visible sign of fractures. The observed clinical signs were hypersalivation; cardiac irregularities (arrhythmia) with off feeding and rapid gasping breathing. On clinical examination observed, mass bleeding injuries along the left lateral maxillae and both hind limbs at umbilical region and also affecting the sacral region with an inability to stand and move. The animal had an open wound at hind limbs which needs to suture and ligation of blood vessels was duly needed so that animal didn't go in shock. The animal has fully restrained with ropes especially the mouth as to be extra vigilant of bite from the animal.

\section{TREATMENT}

As hyena belongs to schedule A list of wildlife act was Treated on a priority basis for early recovery. Firstly animal was effectively restrained and local anaesthesia $2 \%$ lignocaine was given at the site of injury for the proper antiseptic dressing of wounds with potassium permagnate and povidine iodine respective. The sutures were applied at the deep wound to facilitate early healing and control of secondary infection at the site of injury. The animal was treated with $500 \mathrm{ml}$ RL IV route, Inj. Melonex $20 \mathrm{ml} \mathrm{IM,} \mathrm{Injection} \mathrm{Amikacin} \mathrm{500mg.ml,} \mathrm{Inj.} \mathrm{Dexamethasone} 10 \mathrm{ml}$ IV Inj. Antihistamine $5 \mathrm{ml}$ and also Inj. Tribivet $5 \mathrm{ml} \mathrm{IM}$.An animal was kept under continuous supervision in PFA (People for Animal) Gaushala in the grilled cage for proper treatment but the animal succumbed due to the internal injuries very next morning. 


\section{RESULT AND DISCUSSIONS}

Food habit is an important aspect of animal ecology. The presence of domestic mammals in the as the result of encroachment of forest also revealed that striped hyena frequently visited human settlements in search of food. Hence a potential conflict between human and wildlife will occur if the wild food resources of this species depleted in their activity range especially outside the protected areas. This case is very much suggestive of facts that wild animals moving more towards human settlements might lead to accidental of the above Hyena. Hence, maintenance and preservation of prey abundance for striped hyena are necessary for avoiding the human-wildlife conflict in this area. It is also suggested that ecological protection of this large carnivore at a larger scale is needed for finding enough diets and temporal activity for resource partitioning patterns as well as ecological sympathy.

\section{CONCLUSIONS}

In the previous year's injury cases and death due to this has constantly increased in wild life animals across the forest areas which is alarming situation and a well planned wild life management programme is required to sustain the and protect the wild life species of all origin. Beside this training of forest personnel's along with awareness of people towards accidents due to speeding on roads in forest covering areas should be specifically given a work plan.

\section{REFERENCES}

1. Ahmed F A M, Takona N Y, Yousif R A, et al. 2012. Some behavioural traits of striped hyena under captive conditions. Journal of Life Sciences Biomed, 2(5): 196-199.

2. Alam M S. 2011. Status ecology and conservation of striped hyena (Hyaena hyaena) in Gir National Park and Sanctuary, Gujarat. PhD Dissertation. Aligarh: Aligarh Muslim University.

3. Bako, A., \& Musa, I. Effect Of Land Use On Road Traffic Accidents In Urban Zaria Area, Nigeria.

4. Prater S H. 1980. The Book of Indian Animals. Bombay Natural History Society. Bombay: Oxford University Press.

5. Debbarma, S., Nigam, S., Martolia, D., Varma, P., \& Midha, S. B. T. Epidemiology of Accident Cases Attending a Tertiary Care Hospital in Kanpur.

6. Kruk H. 1976. Feeding and social behavior of the striped hyaena (Hyaena hyaena). East African Wildlife Journal, 14: 91111.Gajera N, Dave S M, Dharaiya N. 2009. Feeding patterns and den ecology of striped hyena (Hyaena hyaena) in North Gujarat, India. Tiger Paper, 36(1): 13-17. 
